\title{
Influence of Dissemination Channels on Utilization of Research Findings in the Management of Environment and Fisheries by the Fisher Folks in Kisumu Municipality Kenya
}

\author{
Onyango G.O ${ }^{1}$, Dr. Bosire. $E^{2}$, Dr Akala. B ${ }^{3}$, Prof Otieno W.A ${ }^{4}$ \\ ${ }^{I}$ (Department of Environmental science, School of Environment and Earth Sciences, Maseno University Kenya) \\ ${ }^{2}$ (Department of Environmental science, School of Environment and Earth Sciences, Maseno University Kenya) \\ ${ }_{3}^{3}$ (Department of Environmental science, School of Environment and Earth Sciences, Maseno University Kenya) \\ ${ }^{4}$ (Restech Maseno Kisumu, Maseno University Kenya)
}

\begin{abstract}
The purpose of this study was to investigate influence of dissemination channels on utilization of research findings in the management of Environment and Fishing Efforts in Kisumu Municipality kenya. The objective of this study was: determine influence of dissemination channels on utilization of research findings. Cross sectional descriptive survey design was used in this study. Households were the unit of analysis. From a study population of 15,179 households, a minium sample of 384 household heads were used, proportionate sampling and systematic sampling were used to select households according to location of study area. Purposive sampling were also used to get key informants. Primary data on dissemination channels affecting utilization of research findings were collected through questionnaires, key informant interviews, Focus Group Discussions, field observation, and photography. The quantitative data were analyzed using descriptive statistics to establish relationships. Qualitative data were analyzed by creating patterns and themes. Finally logistic regression analysis were used to establish influence of channels of dissemination on utilization of research findings to answer the research questions. The regression output shows that the relationship between channels of accessing research findings and its utilization was positive $r=0.194$ variation $R^{2}=0.38, \beta 0.194$, $p<0.05$ channels of dissemination influence utilization of research findings among fisherfolks. The study concluded that there was a strong relationship between the channel of dissemination of research findings and its utilization by fisher folks. The study recommended that the scientific community/researchers should be encourage to be more open with their findings, to publish/disseminate their findings using channels of disseminations which are accessible to more and more people who can access and learn from them so that they can reduce pollution going on in the lake.
\end{abstract}

Keywords: Channels, Dissemination, Research Findings, Utilization, Fisher folks

\section{Introduction}

Globally, the natural environment has been threatened by the human activities which involve extraction of its resources and pollution. This has affected both the terrestrial and aquatic environment which support organisms, to some extend biodiversity are threatened. The Lakes, Reservoirs and Rivers are among the most extensively altered ecosystem on the earth. Transformation include changes in morphology of Rivers and Lakes, Hydrology, Biogeochemistry of Nutrients and toxic substance, ecosystem metabolism and storage carbon, loss of native species, expansion of invasive species and disease emergences (Stephen et al., 2011). The key drivers of this threat to the global environment are (a) population growth (b) pollution of our natural environment (c) climate change and (d) over exploitation of our renewable and non-renewable resources (David et al., 2006). Much remains to be done to engage the global citizens to reverse this threat to our environment through dissemination/ utilization of research findings or doing further research on how to create awareness on degradation of environment to reverse the process.

Population growth has been the main driver in environmental degradation/modification, at the moment it has become difficult to understand and predict how environmental changes will interact since many parts of the earth have been polluted in one way or the other (Novine et al., 2010). In Asia which has been experiencing high population growth which has also come with its own demands and challenges. Among the demand and challenges are demand for more fire wood, more Agricultural land to grow more food, increase sanitation challenges due to increase of more informal settlements and processing of waste generated has been a problem. Apart from this, more nutrient enrichment of water bodies has been taking place from untreated sewage discharge, and erosion of nitrogen fertilizers which are used in Agricultural activities. In China particularly, $47 \%$ of the wet lands are manmade composed of rice paddy and fish ponds (Wolfgang et al., 2013). This has led to Algae bloom in the water bodies which is a health risk to the surrounding population. The question is, are the people of China aware of this emerging challenges of environmental degradation and what are they doing to 
address it? Probable various research done on environmental issues are not reaching the people to use them to address these challenges. A similar situation is taking place right here in Kenya particularly Lake Victoria Kenya where serious degradation of environment is taking place, just like China the public need to be involved and educated to conserve the environment to reverse this trend.

In South America which covers an area of 17.8 million $\mathrm{km}^{2}$ environmental degradation is still a big problem, the population of the continent has been growing very fast and currently stands at 381 million people. The end result has been environmental degradation where more and more waste products are not being managed properly and nutrient enrichment is taking place in water points resulting in Algae bloom (Wolfgang et al., 2013). This is particularly experienced in Brazil which is a good example where there has been growth of Agroindustries and urbanization which has resulted in discharge of waste water without treatment into rivers and water reservoirs. The occurrence of toxic cyanobacterial bloom has been registered in 11 out of 26 Brazilian states from North to South. These blooms occur mainly in reservoirs but there are records of occurrence in several coastal lagoons, natural lakes, rivers and estuaries. In general, there is little information about cyanotoxin analysis or toxicity test done with cyanobacteria bloom material. The consequences of toxic cyanobacteria bloom occurrence are underestimated or undiscovered by different authorities responsible for the environment and water quality control, the management actions, preventive plans and remedial measures are usually only implemented when a serious event occurs. It is common to observe that these actions are restricted to a few weeks surrounding the event, depending on the media attention for the case (Ingrid, 2005). In Brazil just like China very little is done to address the degradation going on and probably due to lack of access and awareness of research findings which have been generated to reverse the process. In this case lack of dissemination of environmental research findings has led to low awareness of effects of environmental degradation and its impact to the environment and population health and this need to be addressed. A similar situation of what is happening in Brazil is happening in Lake Victoria Kenya and this formed the basis of this research; to find out why research information generated has not been disseminated and utilized to conserve the environment.

Lake Victoria is the second largest fresh water Lake in the world with surface area of $68,000 \mathrm{~km}^{2}$ (Linda et al., 2003) and it is shared by three East African countries namely Kenya, Uganda and Tanzania. Kenya occupy $6 \%$ of water mass, Uganda occupy $43 \%$ of water mass and Tanzania which has the largest share of 51 $\%$ of water mass (Regional Frame survey Report, 2012). The Lake has a catchment area of 193,000km ${ }^{2}(\mathrm{Uganda}$

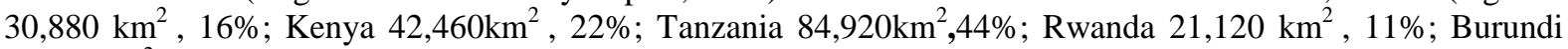
$13,510 \mathrm{~km}^{2}, 11 \%$ ) with a rapidly growing population of over 35 million people World Bank, (2009). The Lake is relatively shallow with a maximum depth of $69 \mathrm{~m}$ (Johnson et al., 2000). The implication of high population growth is more of socioeconomic activities which is degrading this ecosystem due to high demand of the environmental resources which is a source of livelihood. As a result of this degradation taking place more dissemination and utilization of environmental and fisheries research findings is needed to utilize this resource in a sustainable way.

Globally an enormous amount of information and data has already been generated, and will continue to be generated in physical, chemical and biological aspects such as limnology, hydrology, climatology, ecology, biochemistry and many more, all of which contribute to a better understanding of the state of the lakes, reservoirs and other lentic water bodies. There is also a growing number of studies on the managerial aspect of aquatic, terrestrial and riparian ecosystems including water quality, sediment quality, shoreline environment, inflowing and outflowing water systems extending to upper watershed tributaries. A needed component not yet produced is a means of compiling and utilising holistically, practically-synthesized information and data on such thematic and disciplined subjects (Research centre for sustainability and environment, Shiga University and International lake Environment committee Foundation, 2014). In Kenya the quantity of data and research on Lake Victoria and its drainage is overwhelming. The number of research done to generate knowledge is estimated at about 405 (LVBC Knowledge management Portal, 2013). The key thematic areas which have been researched on are aquatic plants, parasites of fish, different species of fish, water budget, invertebrates, human socio-economic activities, pollutants discharged in Lake Victoria and climate change effect on Lake Victoria Basin, just to mention a few. These environmental and fisheries research findings are important to the people living and working within the Lake Victoria Basin depending on their socio-economic activities. Out of 405 environmental research findings, it is interesting to note that 9 has been done to address the subject of how best the research information generated could be utilized in solving the emerging environmental degradations and fisheries problems. This suggests low adoption of research findings hence this needed to be examine on factors that influence their dissemination and hence low doption.

Despite all these environmental and fisheries research findings done so far, ecosystem health degradation is still a threat in Lake Victoria and its Basin. The major challenge might be lack of access and awareness for utilization since most of the findings are published in international journals not accessible by fisher folks. The other problem might be lack of Resource Centre where various researches conducted can be 
stored for easy access to create awareness for utilization by fisher folks or may be a problem exists on how the research findings are disseminated to fisher folks or may be dissemiation does not exist at all. This dissemiation helps to create an informed society which is a prerequisite to conservation efforts (Ogutu-Ohwayo et al., 2006). After considering the availability of environmental and fisheries research finding, it would appear that further research may not be the main priority but rather dissemination and utilization of existing information for sustainable management of LVB resources. Therefore, despite the growing interest in the concept of utilization of environmental and fisheries research findings for sustainable management of LVB. There remains important knowledge gaps on dissemination channels on one hand and utilization of environmental research findings generated and fishing effort on the other hand which calls for further research on dissemination chanel.

\subsection{Statement of the Problem}

Despite many studies having been done around LVB on water quality, policies, conservation issues and challenges, climate change, water budget, fishing gears and cultural issues of communities, little attention has been given on how well the environmental and fisheries research findings can be disseminated to create awareness for utilization to conserve lakes's resource among the fisher folks. The challenges facing the lake are still persisting and getting worse. There is not much information available which address how best the environmental and fisheries research findings can be disseminated and utilized to address the current challenges facing the LVB. Lake Victoria is an important ecosystem within LVB because it support a variety of socioeconomic activities e.g. tourism, fishing and agricultural activities which are the mainstream of livelihood for many people. These activities have partly contributed to the increase in the human population in the area surrounding Lake Victoria Basin, and have posed a number of challenges to sustainable use of the ecosystem due to over-abstraction of water and other resources, loss of biodiversity and pollution of the Lake in Kenya where the study area is located, Uganda and Tanzania. However, on this note little research has been conducted dissemiation channels factors influencing utilization of environmental and fisheries research finding by Fisher folks who depend on the Lake for livelihood. Likewise, the various channels used in dissemination of environmental research findings and its utilization are not clear. Furthermore, the relationship between the fishing effort and BOD, pH, Temperature, Turbidity, number of fishers from 1997 to 2011 is not well documented to create awareness to the fisher folks. This puzzling situation raises a fundamental question as to what might be the reason for the mismatch between available environmental research findings and continuing environmental degradation of LVB. It is against this recognition of this gap that this study sought to determine influence of dissemination channels on utilization of research findings in the management of environment and fisheries by the Fisher Folks.

\section{Literature Review}

Various researches which have been conducted within LVB ranging from policies, biodiversities, impact of human activities, conservation issues, agriculture and forestry, socio-economic activities, climate change and adaptation, water budget, cultural issues, water quality issues among other (www.project.csg.uwaterloo.ca/ivbc). These research findings were aimed to be harnessed and disseminated by LVBC for creating awareness and utilization for sustainable manage of LVB which may not be apparently taking place. LVBC did not go further to investigate how dissemination channels is affecting utilization of research findings for sustainble management of LVB. This can be observed through current degradation taking place within the LVB. Either people are not aware of the environmental research findings or the method of dissemination is not appropriate or they are ignoring the findings. About 405 study research findings have been done so far on issues affecting LVB, but the findings did not go further to demonstrate how the environmental and fisheries research findings are disseminated and utilized by the fisher folks. This formed the basis of this research. This research established the influence of dissemination channels on utilization of environmental and fisheries research findings.

Another related research by Ogutu-ohwayo et al., (2006) which had been done on management challenges of fresh water fisheries in Africa is not very clear on dissemination channels. The fresh water fisheries of Africa are important sources of income and protein for the people of the continent and stock of biodiversity for the world. The report discussed the experience for eight important lakes (Baringo, Chad, Kariba, Malawi, Naivasha, Nakuru, Tanganyika and Victoria), in order to provide an overview of the challenges facing the African freshwater systems, the interventions undertaken to manage the challenges, the inputs that have been required, and the lessons learned to guide further actions. The overall experience indicate a lack of awareness to create effective management actions, as a result of limited accessibility and utilization of scientific information, poor dissemination of management information, in appropriate and unharmonised fisheries laws and regulations, inadequate enforcement of existing laws and regulations, weak institutions and institutional processes and inadequate funds for implementing fishery programmes. The research discussed about the challenges and findings of the research on what Lakes in Africa are going through, this concurs with what has been observed in 
Lake Victoria but the study did not investigate the influence of channels of dissemination of research findings on its utilization. This formed the basis of this research which established the influence of channels of dissemination on utilization of environmental and fisheries research findings for sustainable management of LVB by the fisher folks. This is anticipated will go a long way to reduce degradation taking place in LVB once awareness has been created.

Another closely related research was done by Onyango et al., (2011) on Utilization of research findings for sustainable management of Lake Naivasha Basin. Result from the research showed that in spite of the many research studies conducted, the research findings have not been able to reach the various stakeholders to utilize them due to lack of accessibility to the information, technical language used were advanced while the majority of the people have low level of education. The gap is no such study has been replicated in Lake Victoria. The study in Lake Naivasha did not investigate the influence of the channels of dissemination of research findings on its utilization. This is what this study in Kisumu municipality seeked to establish. Lake Victoria and Lake Naivasha shared many similarities in terms of pollution of the lakes, high socioeconomic activities, overpopulation and problem of discharge of raw sewage. The only difference is that Lake Naivasha has high concentration of flower farm companies which contribute to pollution of Lake.

\section{Research Methodology}

This study was conducted in Kisumu East District which is located on the western region of Kenya in Kisumu county at $34^{0} 42^{\prime} 49^{\prime \prime} \mathrm{E}$ to $34^{0} 46^{\prime} 47^{\prime \prime} \mathrm{E}$ and $00^{0} 06^{\prime} 14^{\prime \prime} \mathrm{S}$ to $00^{0} 01^{\prime} 13^{\prime \prime} \mathrm{S}$. It is one of the three Districts found in Kisumu County namely Kisumu west, Kisumu East and Nyando. Kisumu East District has two divisions Winam and Kadibo. It has twenty locations namely; Kondele, Kolwa Central, Kolwa west, Kolwa East, Kisumu South West, Kisumu Central, Kisumu East, Kisumu North, Kajulu East, Kajulu West, Miwani, Kawino North, Kawino South, West Kochieng, East Kochieng, Komura, Bwanda, Katho and Kanyagwal. The study area falls between at $34^{0} 35^{\prime} 52^{\prime \prime} \mathrm{E}$ to $34^{0} 47^{\prime} 22^{\prime \prime} \mathrm{E}$ and $00^{\circ} 09^{\prime} 27^{\prime \prime} \mathrm{S}$ to $00^{\circ} 02^{\prime} 55^{\prime} \mathrm{S}$. The size of Kisumu East District is $559.2 \mathrm{~km}^{2}$ (ROK, 2009).

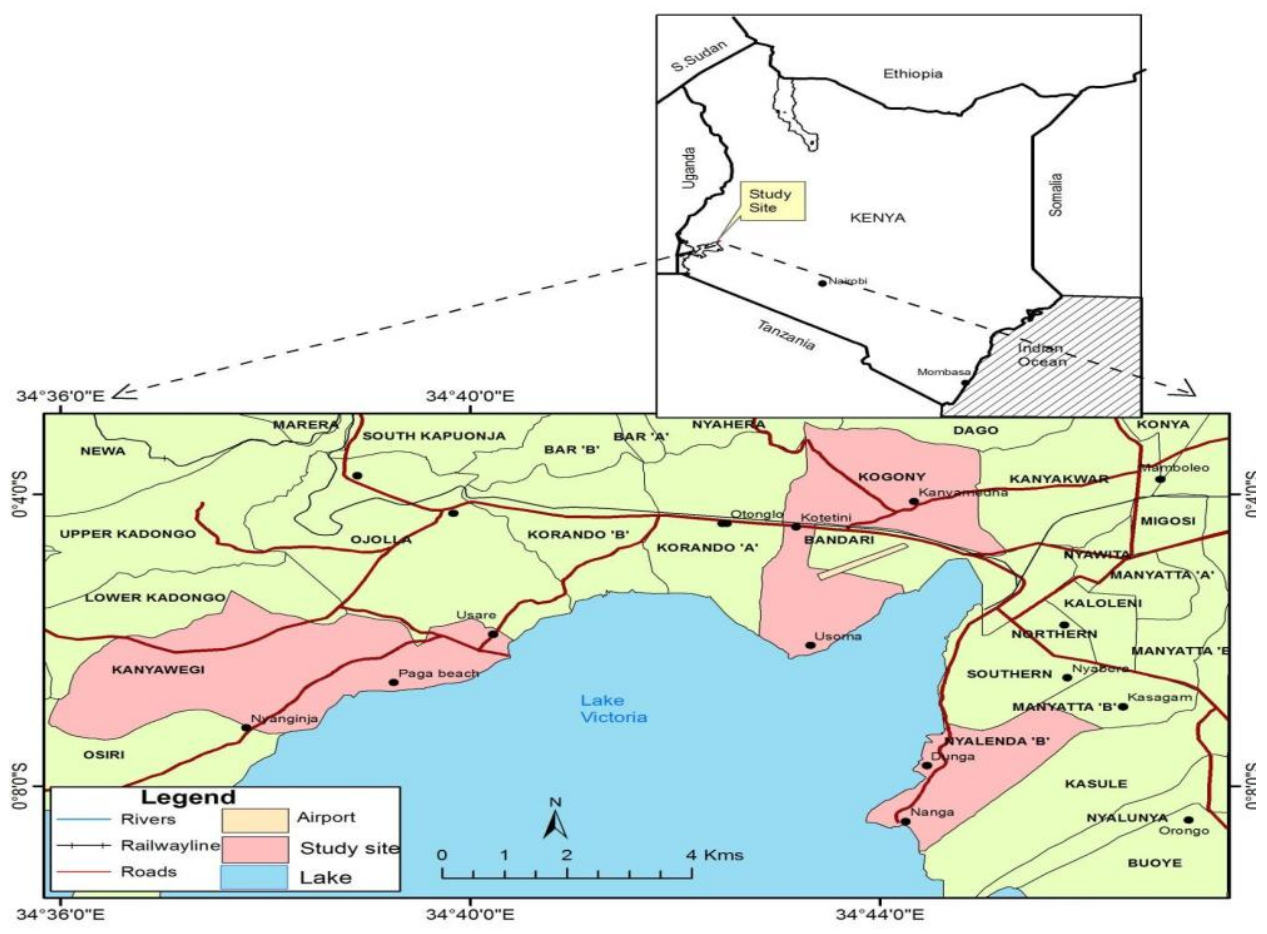

Figure 1: Map of Kenya Showing the study area Kisumu Municipality.

The study adopted a cross-sectional descriptive design. The unit of analysis was the households and the respondents were household heads. From a study population of 15,179 households, a minium sample of 384 household heads were used, proportionate sampling and systematic sampling were used to select households according to location of study area. Purposive sampling was used to sample Key informants who are not fisher folks and are knowledgeable about the situation within LVB. These included one for each group; Fishery officer, Kenya Wildlife Services, Agricultural officers, Area chief, leader of BMU, NGO, CBO and Minister of Fisheries in Kisumu County Government. Questionnaires, interviews, focus group discussion, and observation were used to collect primary data on dissemination channels factors affecting the utilization of environmental 
and fisheries research findings among the fisherfolks. The quantitative data on the influence of channels of dissemination on utilization of environmental and fisheries research findings among the fisher folks was analyzed using descriptive and inferential statistics.

\section{Findings of the Study}

Going by the current state of the environment surrounding LVB particularly around the lake the environment is dirty and the volume of fish harvested from the Lake is on a declining state. When the respondents where asked if the environment is degraded; $86.70 \%$ mentioned it was degraded and $13.30 \%$ mentioned it was not degraded (Figure 2). That alone send a strong message that enough work is not being done to protect environment right from individual level to Goverment level. The degradation of the lake and its basin concurs with the studies which demonstrated that the catchment areas of lake victoria is slowly being degraded due to deforestation and couple with bad Agricultural practices which lead to siltation of the lake. Industrial and domestic effluent are also polluting the lake by increasing the nutrient loads (Sixtus and Sven, 2003).

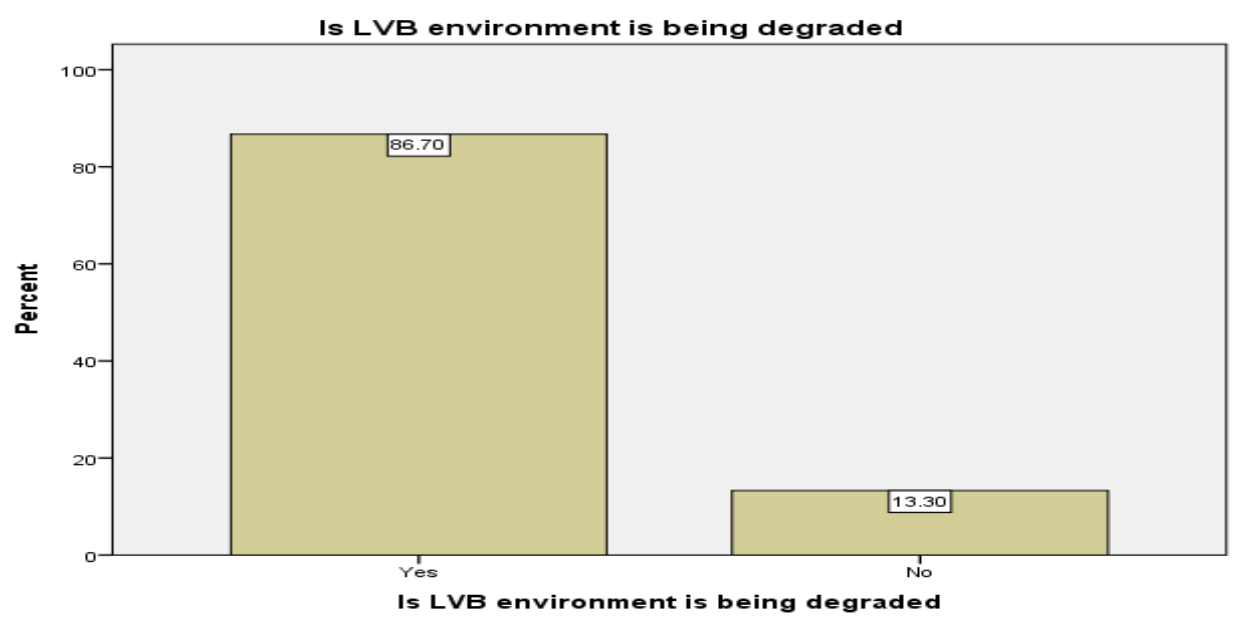

Figure 2: Response of respondents on status of degradation of LVB

When the respondents were asked further what were the indicators of environmental degradation; $12.5 \%$ mentioned water hyacinth, $21.43 \%$ sewage/industrial discharge into lake/dirty water, $1.28 \%$ population increase, $9.69 \%$ poor solid waste management, $1.28 \%$ out break of water born disease, $18.11 \%$ had no idea of indicators of environmental degradation, $0.77 \%$ frequent crocodile attack, $4.85 \%$ destruction of papyrus reeds which are breeding site for fish, $7.14 \%$ at times stambling on dead fish in the lake, $2.55 \%$ climate change, $0.77 \%$ building structures along the riparians of the lake, 3.06\% bad oduor from the lake water and 5.36\% soil erosion (Figure 2). From this data its clear the respondent were aware the environment is being degraded and this is caused mainly by raw sewage and industrial discharge. From the observation sewage lines are not in good working condition and this discharge the sewage water directly into the lake. In this case River Kisat and river waigwa are the most affected. As captured in the NEMA (National Environment Management Authority) report of the state of the environment of 2013/2014. This rivers have been indicated as having been marked by NEMA and they are monitoring how they are affecting the lake ecosystem (RoK, 2015). What this report is not saying what action are the NEMA taking interms of enforcing the law to restore the ecosystem. Again in this report Kachok dumpsite has been list as one of the high risk facility in Kisumu and NEMA is monitoring the facility from GIS how its expanding and affecting the surrounding population and the lake. What NEMA again is not saying in the report what steps are they taking to restore the area. When one check the revised EMCA Act of 2015 , it state clearly what steps can be taken by NEMA to restore the environment. The question is why is NEMA relactant and they are backed with robust law? The issue of NEMA not up to task to protect the lake also came up in FGD in Dunga Beach where one particpant mention its doing a poor job to protect the environment by not enforcing the law. 


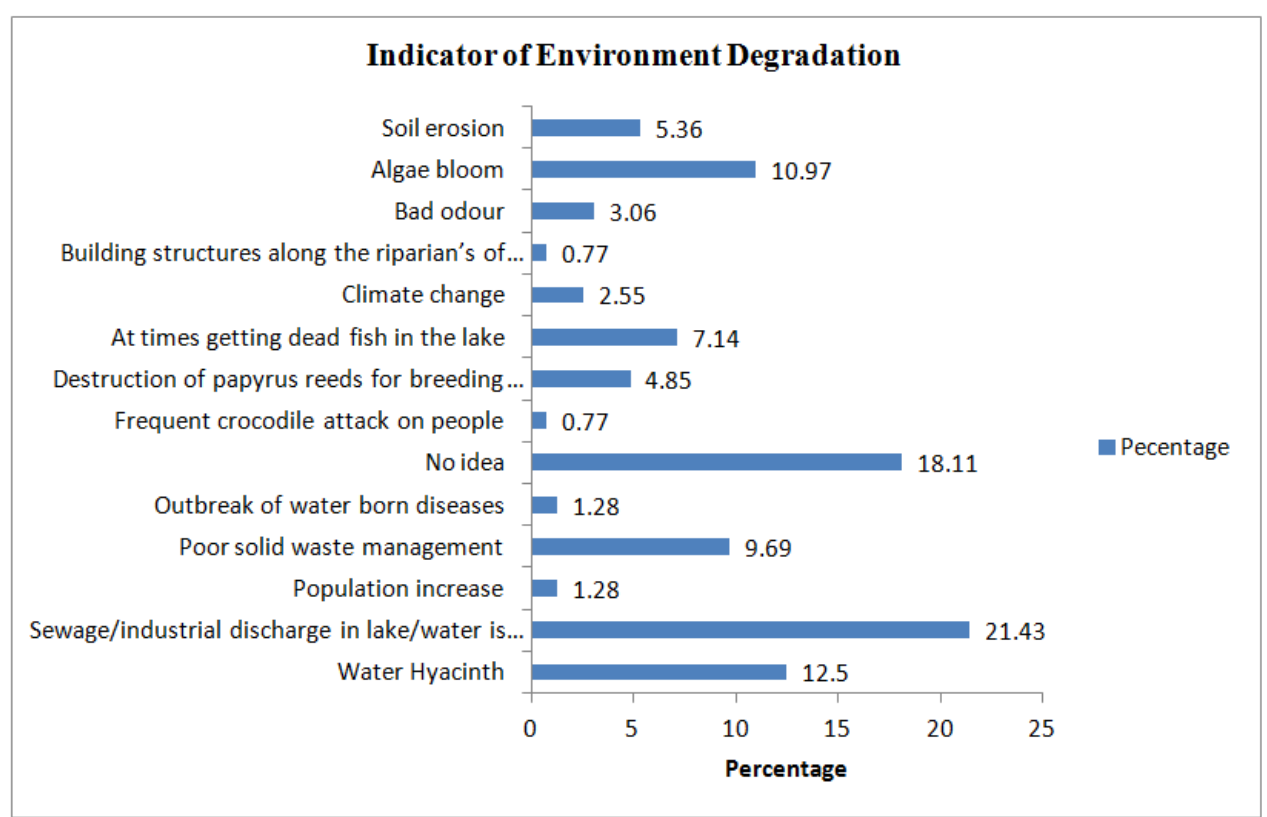

Figure 3: Indicators of degradation as mentioned by respondents

When repondents were asked to state where they get research findings to address issues related to environment; $24.1 \%$ had no idea where to get it, $17.95 \%$ get information from neighbours and friends, $20 \%$ from NGOs, $14.62 \%$ from Government offices, $11.79 \%$ from chiefs, $8.46 \%$ from research institutions, $2.82 \%$ from radios, and $0.26 \%$ from schools (Figure 4). The same pattern was replicated for fisheries though with different percentages. Now if the majority of respondents get information from neighbours and friends and again another group has no idea. All this, if combined makes $42.05 \%$ which is close to $50 \%$ of the respondents. From this findings, it demonstrate that research findings are not reaching half the respondents so that they can use them to address the challenges affecting the environment. When this findings are extrapolated then half the population in the study area are not getting correct information or they are not getting research information at all. This also probably explain why their is low awareness of research findings among the respondents. The research information shared among the respondents from neighbours and friends is probably distorted and does not represent facts of what is happening in the environment and fisheries. Something which also emerged is that few respondent are using radio too to access research findings. Probably the reason most research information are not channeled through the radio, though Radio are cheap and can be afforded by many households is because programs have not been developed which can be aired through it. This concurs with studies which demonstrated that there exist suffient knowledge base for informed lake management, particularly the fishing sector. However, the mass of information from projects has yet to be assembled into management-friendly and communityfriendly packages for use to create awareness among the fisherfolks. Until when this is done, information will not reach the communities around Lake Victoria (Sixtus and Sven, 2003).

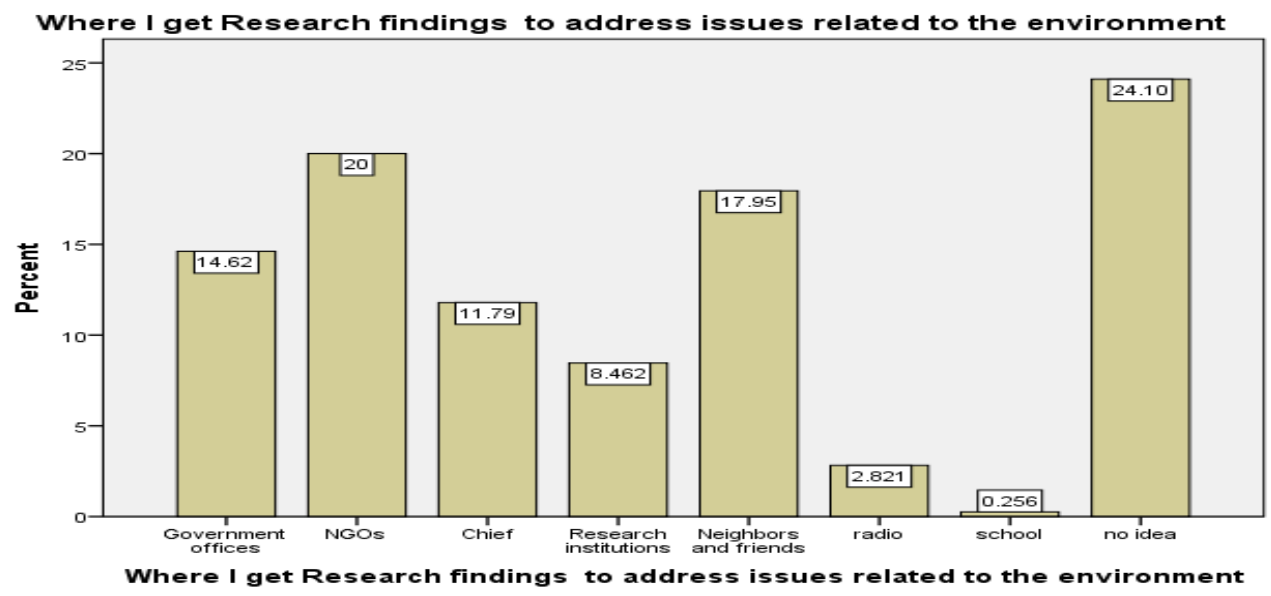

Figure 4: Sources of research findings 
When the respondents were asked to state the frequency of using of the various channels to access the various research findings they stated as follow; Public Baraza 26.68\% never used it, 24.35\% rarely used it, $24.35 \%$ occasionally used it, $17.10 \%$ often used it, $7.51 \%$ frequently use it (Figure 5). From this findings accessing research findings through baraza is low probably due to the fact that many people do not attend them, its proving to be unpopular.

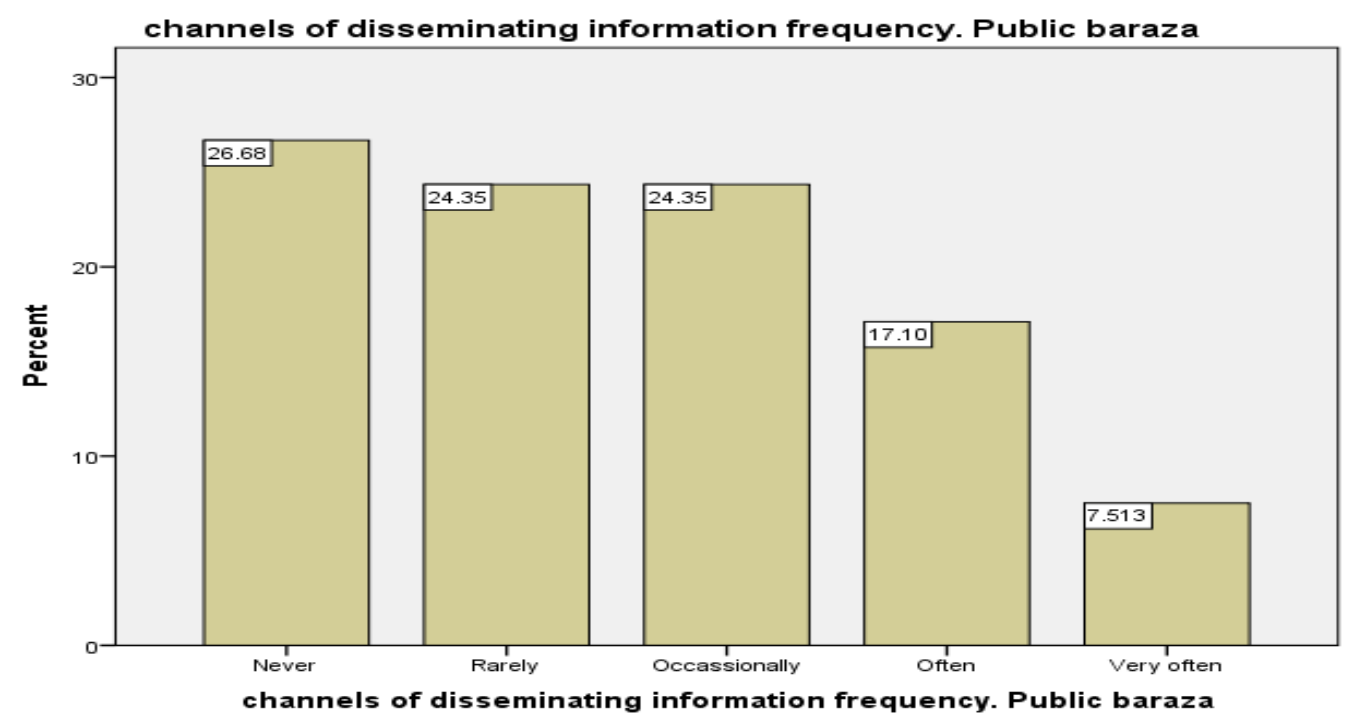

Figure 5: Frequency of disseminating information by public baraza

For the Radio; $6.14 \%$ never listen to radio, $11.51 \%$ rarely listen to radio, $17.65 \%$ occassionally use radio, $31.97 \%$ often use the radio and $32.74 \%$ very often use the radio (Figure 6). From this information more and more respondents depend on radio for for news and probably other programs such as information on environment and fisheries. Radio is more commonly used because it can be afforded by most of the respondents households as explain elswhere in this study.

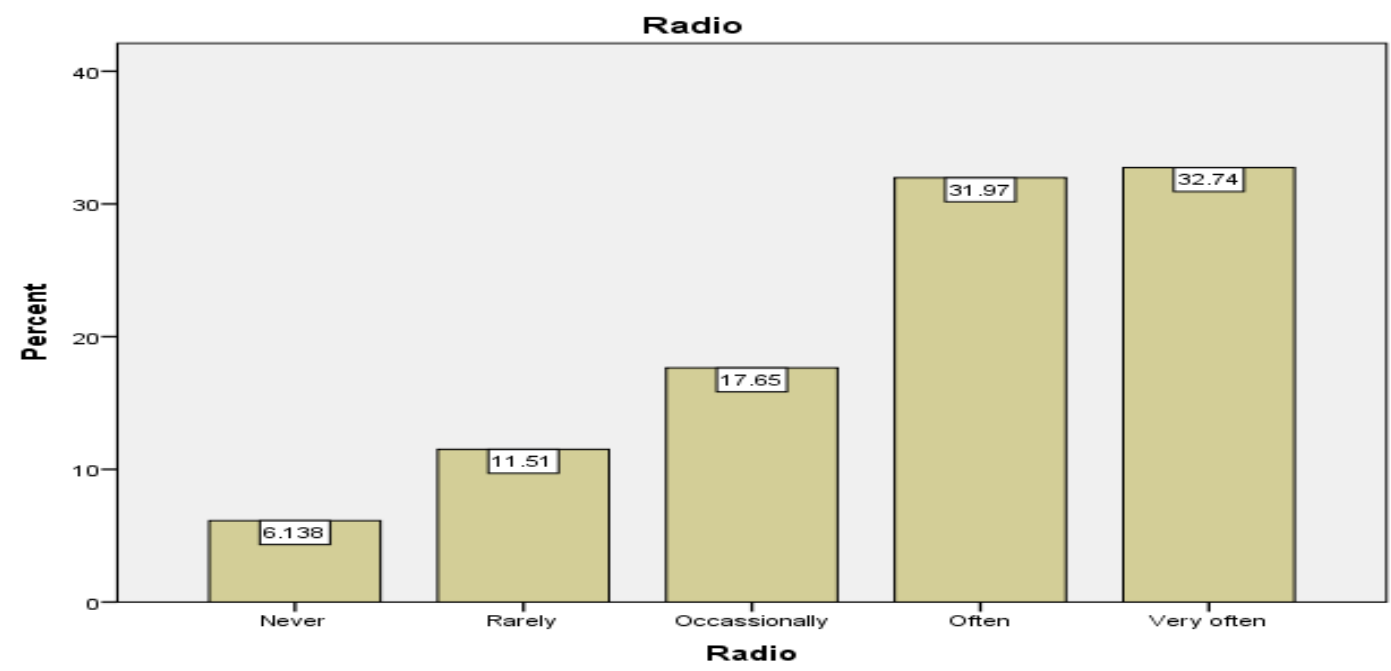

Figure 6: Frequency of dissemination of information by radio

For Television; $27.32 \%$ never use it, $21.13 \%$ rarely use it, $18.56 \%$ accasionally use it, $18.20 \%$ often use it and $14.69 \%$ very often use it. From this information, few respondents depend on TV for information on environment and fisheries research findings due to the facts that probably its viewed as expensive to acquire and also one has to pay monthly subscription to access information using it (Figure 7). This maybe has discouraged many viewers from using it. 


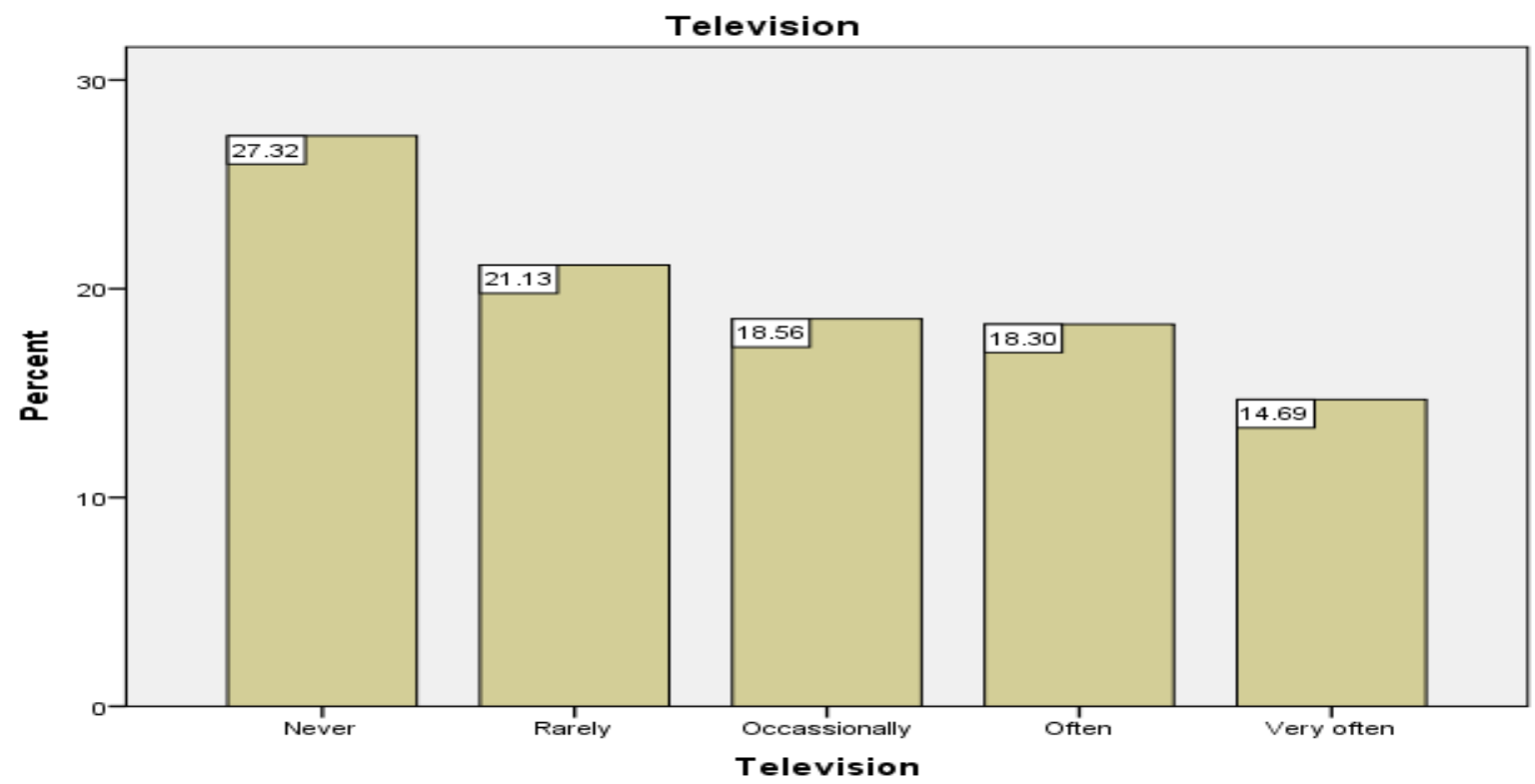

Figure 7: Frequency of dissemination of information by Television

As regard to the use of internet; $54.10 \%$ never use it, $18.72 \%$ rarely use it, $12.56 \%$ occassionally use it, $7.95 \%$ often use it and $6.67 \%$ very often use it. From this information very few respondents use internet to access environment and fisheries research findings this is probably due to the fact that the cost of acquiring internet enable phones is high and the cost of purchasing internet bundles is also high. The other fact which may be contributing may be lack of know how to use this phone among the respondents. While this remain the best channel of get information on latest research on environment and fisheries (Figure 8) its not used very much by the respondents.

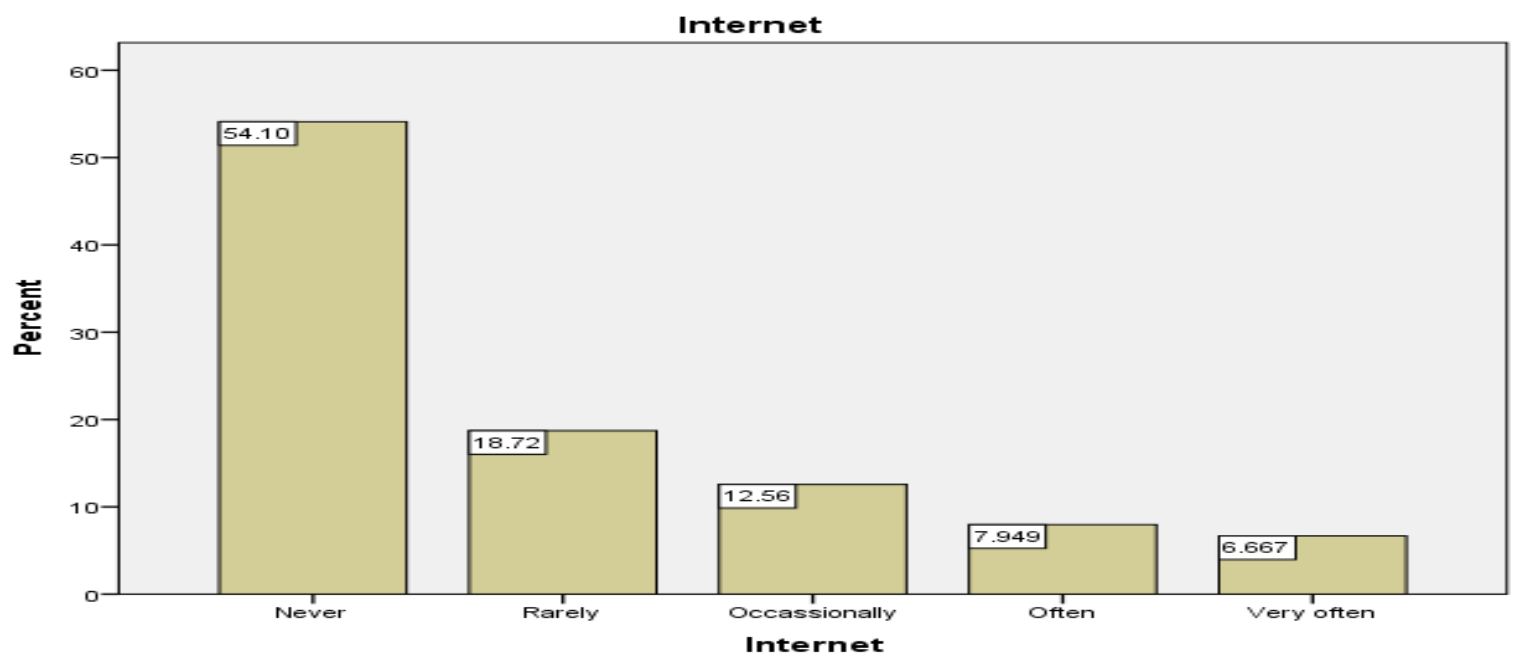

Figure 8: Frequency of dissemination of information by internet

For newspapers; $39.18 \%$ never read newspapers, $24.48 \%$ rarely read newspapers, $24.23 \%$ occasionally read newspapers, $8.51 \%$ often read newspapers and $3.61 \%$ very often read newspapers (Figure 9). In this situation as explain elswhere in this research findings, most of the respondents are poor, depend on small scale business, so the issue of affording to buy newspapers everyday becomes a big challenge to them. Most of this people are preoccupied with sources of livelihood which can meet their daily needs. This probably explain why $3.61 \%$ of the respondents buy newspapers because buying newspaper which cost $60 /=$ a day is not easy since respondents will view this as money which can be spend to take care of their daily needs. It is in newspapers that one get the current affairs on issues affecting our environment and fisheries apart from other information. 


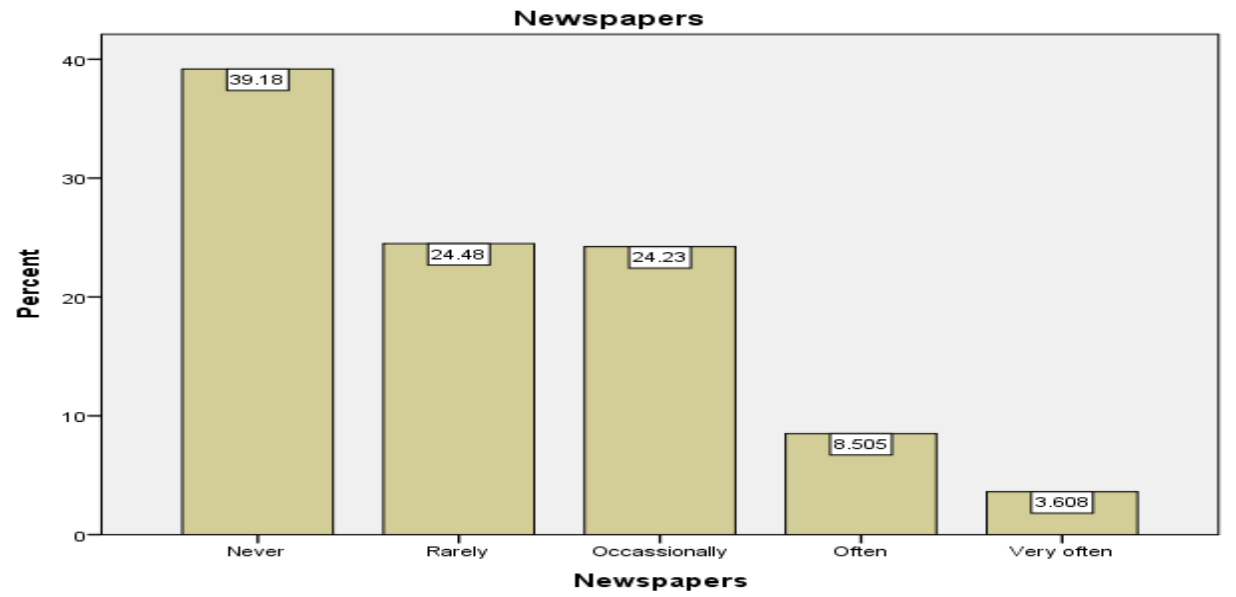

Figure 9: Frequency of dissemination of information by newspapers

When the respondents were asked what are the major challenges they face in utilizing research findings; $35.97 \%$ mentioned researchers do not share their research findings with them, $18.62 \%$ mentioned poverty, $25.77 \%$ had no idea, $7.65 \%$ language barrier was a challenge to them, $10.20 \%$ lack awareness/ commitment and $1.53 \%$ mention corruption was a problem since when they go to research institution to get research information the officers concerned ask for bribe which they do not have. From this findings it paint a picture of lack of proper channel of accessing various research findings which have been generated, this might be due to lack of proper dissemination channels. Or it may be the respondents are accessing it but they are not able to comprehend and understand the research findings so that they can use it to address the environmental and fisheries challenges facing the lake. Also of concern is the poverty level which is affecting the respondents, this is an impediment in accessing and utilising research findings since it goes with affordability. Most of this research findings for you to access them you have to pay some fees to most government run institutions such as research stations (Figure 10). This probably explains why the awareness is low and why the degradation is continuing to take place. This concurs with (Kelly, 2009; Wandiga et al., 2006) studies which states that public awareness and participation need to be raised among elected officials, local communities and the general public on research findings so that they can use them to conserve the environment. This is supported by Fredrick et al., (2011) studies which stated that empowerment process among the riparian communities should be triggered and strengthened so that they could themselves participate in decision making process of fisheries management in order to be able to fight these ills to create favorable living environment and sustainable income base.

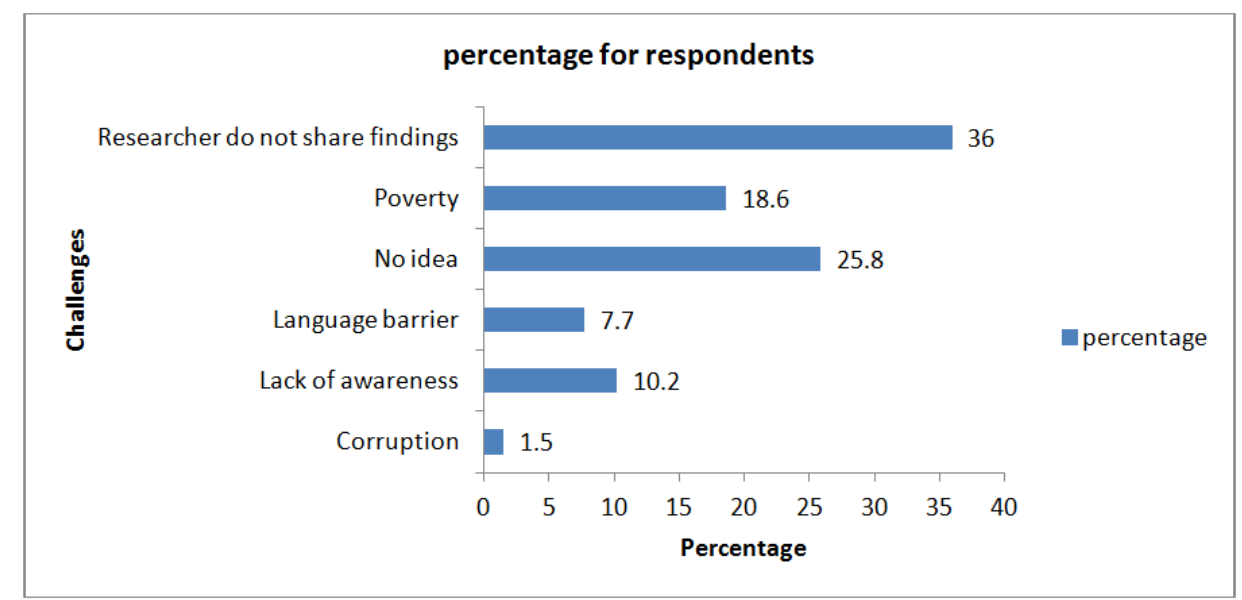

Figure 10: Challenges of utilization of research findings

When the respondents were asked to suggest on ways of how to improve on utilizing research findings; $25 \%$ mentioned researchers to share research findings through baraza/radio/use simple language, $38.52 \%$ mentioned create more awareness about existence of research findings, $1.53 \%$ mentioned information centres for storing research information should be build and $27.04 \%$ had no idea on what was to be done (Figure 11). From this finding it paint a picture of respondents who some how have an idea of existence of research findings and has challenges in utilizing the information. The suggestions respondents gave point to the fact that 
they are interested in utilizing the information which has been generated to restore the lake and use it in a sustainable way. From this information also large number of respondent have no idea on what to do when it comes to issues of utilizing research findings. This is very worrying information because respondents probably cannot access research findings to create awareness and use it to address the various challenges affecting the environment and fisheries so that they use the lake and its environment in a sustainable way.

Currently as a result of lack of proper access of research findings information which has been generated to create awareness among the fisherfolks, its not clear whether the shortage of fish is as a result of pollution of the lake or as a result of increased population which has triggered high consumption of fish. From the article (The Standard correspondent, 2016 July $4^{\text {th }}$ ) it stated that the Kisumu market is flooded with Chinese fish, it goes further to state more fish consumed in this town also come from Turkana too. Interestingly the fish from China are cheaper than fish from Kisumu for example Chinese fish goes for Sh.30.00 a piece while the local fish from lake victoria goes for between Sh. 100.00 to Sh, 200.00 a piece. Since the time this information became public it triggered debate over the social media and newspapers why the importation of fish in Kenya and the opinions were divided over this issue where the fishfolks and policy makers are seeing the lake differently. According to the article ( Daily Nation correspondent, 2016 August $8^{\text {th }}$ ) "Stop demonising the Chinese; Manage Lake Victoria better" authored by Magaga Alot, he was very clear we need to start thinking how best we can manage the lake to unlish it's potential since the lake has been neglected by the Governments of the three East African States for many years. He advice the three East African States instead of getting angry with China, they should recognise the short comming/problems and provide inspirational leadership to unlock the potential of lake victoria. What the author is saying is the three countries are not working together for the betterment of the lake for its citizenry. This information concurs with the findings of this research in the sense that most respondents feel that the lake has been neglected by the Government and that is why pollution level have been left to continue, and worse still they feel the research information generated is not being diseminated to them to know what is affecting the lake as this their source of livelihood and whatever affects it is making them more and more poor. This also concurs with studies Wandiga et al.,(2006) where the management of the Lake Victoria Basin in a sustsinable way require good political will and policy direction from five member states (Kenya, Uganda, Tanzania, Rwanda and Burundi).

In the article (Nation correspondent, 2016 August 12 $2^{\text {th }}$ ) "The myth of Kenyan's sudden love for fish and cooked up data" authored by Mark Evan Ondari, waded into the mucky debate of the fisheries and added a new twist in it. He stated that the Principle Secretary for Fisheries Prof Japhet Michemi Ntiba says that Kenyans consume one million tonnes of fish and the country is only able to produce 200,000 tonnes per year. The short fall which the country is facing is 800,000 tonnes and has to be met by importation. This translate to comsumption of 20 kilogrammes of fish per person per year for a population of say 50 million people. What the Author questioned is why did the Principle Secretary Fisheries Prof Ntiba contradict himself in October $16^{\text {th }}$ 2012 where he stated that Kenyans are not eating enough fish to sustain fish farming in Kenya which translate to consumption of 3.7 kilogrammes of fish per person per year and want to raise the consumption of fish to 10 kilogrammes of fish per person per year to ensure farmers have enough market for fish. Further more the author continues to state that Kenyans consume between 5 to 6 Kilogrammes of fish per person per year according to United Nation Food and Agriculture Organization. According to him the information by Prof Ntiba is not correct and wondered why would anyone want to cook up fish consumption data to create artificial shortage to justify importation of cheap fish in the country from China he asked? The main reason is to import and sell it for a profit he added. He goes on to explain that since fish is harvested from the western and coastal region of the country, historically this are opposition strongholds and this data is calculated to subotage these areas economically. The information from the author concurs with the findings from the FGD in Dunga and Usoma beach where the participants questioned why the Government is not concerned with the problem affecting the lake and the fisherfolks who are wallowing in poverty but is doing more to uplift the sugar cane, cotton and others sectors within the economy and by extention reducing poverty in those areas. The problem of fish dwindling in lake victoria found its way in Kisumu county Assembly where some MCA wanted 10 million fingerlings released into lake victoria to restock it. This is quite interesting and the beging question will this solve the problem facing the lake? The answer is no since awareness need to be created so that people own the problem and then they find the way forward. From this two articles it point to a problem in utilization of research findings from the researcher to the fisherfolks and the policy makers. Either this information is not reaching the users who may need it, or they are getting the information but they are ignoring the findings. Currently their is confusion in the use of research research findings and the problem affecting the lake can be corrected when this findings reach all the people to create awareness so that they use LVB sustainable. 


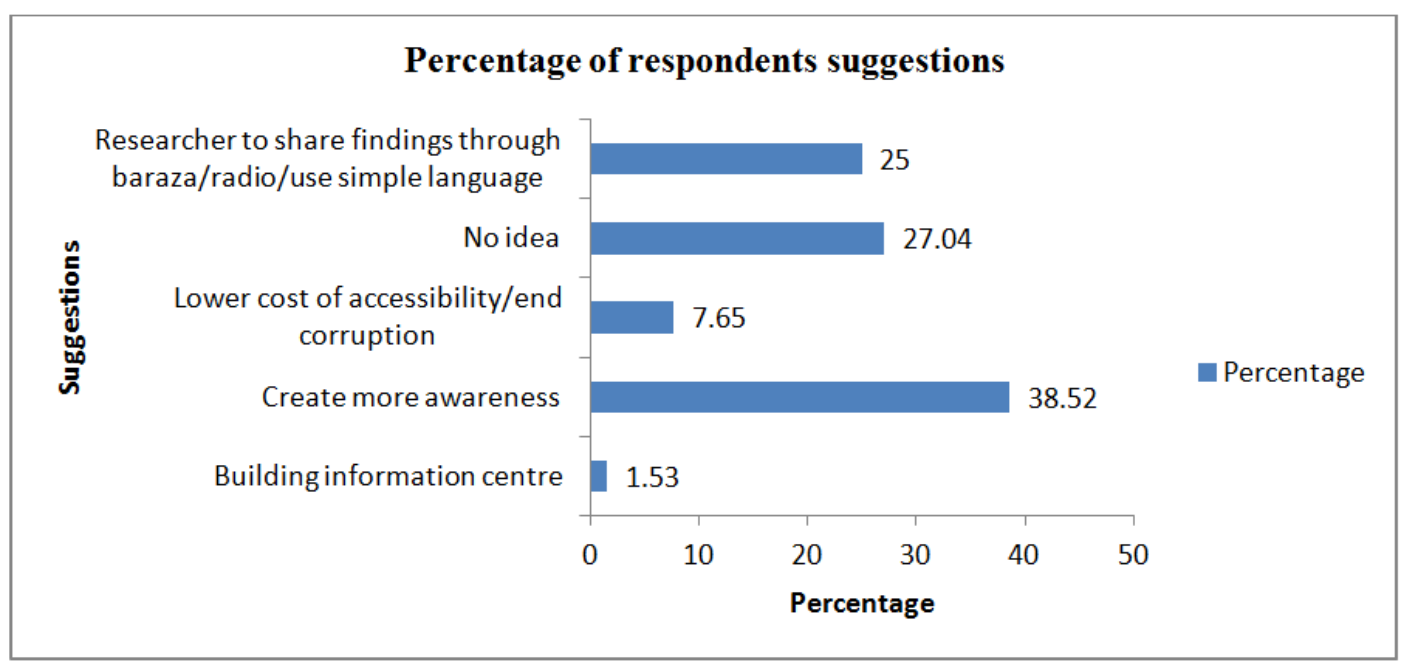

Figure 11: Suggestion on improving utilization of research findings

The findings on the channels of dissemination index; Radio was ranked as the most preferred channel of receiving research finding $\mathrm{N}=388$, Mean 3.75 and Standard Deviation 1.20 (Table 1). At the same time big variation exist in the utilization of radio for accessing research findings information since those access information get it completely where as those who don't get it don't get it at all. In ranking this was followed by Television then Public Barazas. Newspapers, pamphlets, fliers and internet were ranked low as channels of dissemination of research findings. This demonstrates a big variation in the utilization of these channels which is probably due to the fact that they are expensive.

Table 1: Channel of dissemination index

\begin{tabular}{|l|l|l|l|}
\hline Channel & N & Mean & SD \\
\hline Public baraza & 380 & 2.54 & 1.25 \\
\hline Radio & 388 & 3.75 & 1.20 \\
\hline Television & 383 & 2.73 & 1.42 \\
\hline Internet & 385 & 1.95 & 1.26 \\
\hline Fliers & 383 & 1.42 & 0.83 \\
\hline Pamphlets & 383 & 1.49 & 0.83 \\
\hline Newspapers & 382 & 2.14 & 1.14 \\
\hline Channels index & 388 & 2.26 & 0.66 \\
\hline
\end{tabular}

Table 2: Relationships between dissemination channels and utilization

\begin{tabular}{|l|l|l|l|l|}
\hline Scale & Unstandardized Coefficients & Standardized Coefficients & t-value & p-value \\
\hline & $\mathrm{B}$ & $\mathrm{SE}$ & Beta & \\
\hline$($ Constant $)$ & 2.18 & 0.26 & & 8.366 \\
\hline Research findings channels & 0.22 & 0.10 & 0.194 & 0 \\
\hline $\mathrm{R}=.194, \mathrm{R}^{2}=.038, \mathrm{R}^{2}=$ Adjusted $=.030, \mathrm{~F}(1,123)=4.830, \mathrm{p}<.05$ & 0.198 \\
\hline
\end{tabular}

The results depicted in (Table 2) indicate that the relationship between channels of accessing research findings and utilization of findings was a positive $(r=.194)$. They also indicated that the explanatory variable explained $3.8 \%\left(\mathrm{R}^{2}=.038\right)$ variation in utilization of research findings and is a significant predictor of the outcome $(\beta=.194, p<.05)$. These results indicate that the channels of dissemination influence utilization of research findings

\subsection{Summary of Findings}

Channels of dissemination of research findings influence the utilization of research findings among the fisher folks for the management of environment and fisheries $r=0.194, R^{2}=0.038, \beta=0.194, p<0.05$

\subsection{Conclusion}

The study concluded that there was a strong relationship between the channel of dissemination of research findings and its utilization by fisher folks. This demonstrate that channels of dissemination do influence utilization of research findings.

\subsection{Recommmendation}

The scientific community/researchers should be encourage to be more open with their findings, to publish/disseminate their findings using channels of disseminations which are accessible to more and more people who can access and learn from them so that they can reduce pollution going on in the lake. 


\section{Reference}

[1]. David, D., Angela, H. A., Mark, O. G, Zen-Ichiro, K., Duncan, J. K., Christian, L., Robert, J. N., Ann-Helene, P. R., Doris, S., Melanie, L.J. S., Caroline, A. S., (2006). Fresh Water Biodiversity: Importance, threats, status and conservation challenges. Cambridge Philosophical Society 81: 163-182.

[2]. Fredrick, J. M., Fredrick, L. M., Raphael, K., (2011). Environmental Quality and Fish Communities in selected catchment Lake Victoria. The open Environmental Engineering journal Vol. 4, 54-65.

[3]. Ingrid, C., (2005). Current approaches to cyanotoxin risk assessment, risk management and regulation in different countries. Federal Environmental Agency.

[4]. Johnson, T.C., Kelts, K., Odada, E., (2000). The Holocene History of Lake Victoria. Ambio29: 2-11.

[5]. Kelley, L., (2009). Cooperation and competition: Managing Transboundary water Resources in Lake Victoria. Foundation for Environmental security and sustainability.

[6]. Linda, M. C., Robert, E. H., Joseph, N., Rose, M., George, D. D., (2003).Distribution and Food-Web Transfer of Mercury in Napoleon and Winam Gulfs, Lake Victoria, East Africa. Journal of Great Lake Research 29(2): 267-282.

[7]. LVBC Knowledge management Portal.,(2013). Listings-Document-Lake Victoria Basin http://project.csg.uwaterloo.ca/lvbc/listing.php.

[8]. Novine, E. D., Robert, E. H., Timothy, B. J., Jouko, S., John, M. D., Maiju, L., Lars, G. R., Charles, P. M., Fran, W., (2010). Metric of Ecosystem status for large aquatic systems.A global comparison.Joural of Great Lakes Research 36: 123-138.

[9]. Ogutu-Ohwayo, R., Balirwa, J, S., (2006). Management challenges of freshwater fisheries in Africa. Lake and Reservoirs Research and Management 11(4): 215-226.

[10]. Onyango, G. O., Wegulo, F. N., Shivoga, W. A., (2011). Utilization of Reseach Findings for Sustainable Management of Lake Naivasha Basin. Conference proceeding Kabarak University: 185-201.

[11]. Regional Frame Survey Report, (2012).Regional Status Report on Lake Victoria Biennial Frame survey between 2000 and 2012 Kenya, Tanzania and Uganda.

[12]. RoK., (2009). Kenya population and Housing Census. Kenya government printing press.

[13]. Sixtus, K., Sven, E. J., (2003). Lake Victoria: Experience and lesson learned Brief. Copenhagen Denmark.

[14]. Stephen, R.C., Emily, H. S., Zanden, J. V., (2011). State of the world's Fresh water ecosystems: Physical, Chemical and Biological changes. Annu. Rev. Enviro. Resource. 36: 75-99.

[15]. Wandiga, S. O., Madadi, V. O., Kirimire, B. T., Kishimba, M. J., (2006). Lake Victoria; Will it support life tomorrow? A case of abatement of pollution and eutrophication of fresh water. United Nation Environment Program.

[16]. Wolfgang, J. J., Shuguing, A., Finlay, C. M., Brij, G., Jan, K., Stephen, A. M., Wiliam, J. M., Richard, D. R., (2013). Current state of knowledge regarding the world's wetlands and their future under global climate change: A synthesis.

[17]. World Bank, (2009). LVEMP II Project Appraisal Document Report No. 45313 AFR 197 pp 